\title{
State-of-Art in China
}

\section{Preface: Environmental Science in China - Research Progress}

\author{
Yong-Guan Zhu* and Zi-Jian Wang \\ Research Center for Eco-environmental Sciences, Chinese Academy of Sciences, PO Box 2871, \\ Beijing 100085, PR China
}

* Section editor (ygzhu@mail.rcees.ac.cn)

Over the last 20 years, China has been experiencing rapid economic growth, which has resulted in heavy environmental pollution nationwide. Environmental pollution poses risks to human and ecosystem health and limits the industrial and trade growth, thus becoming a major obstacle for China's sustainable development in the new century. Recently, the Chinese central government has adopted a scientific concept of development, which encompasses the principle of comprehensive, co-ordinate and sustainable development, to nurture both the economy and the society. With this new fundamental policy, research on environmental science and technology is facing greater challenges and unprecedented opportunities in China. To continuously combat and mitigate the problems associated with environmental degradation, major research programs are being funded through the Ministry of Science and Technology, the Natural Science Foundation of China, as well as other governmental agencies and industrial consortia. Some of the key research topics are as follows:

- Catchment-based understanding of non-point source pollution and the development of cost-effective strategies to combat nationwide eutrophication of surface water bodies;

- Development of cost-effective remediation technologies for contaminated sites, including soil and (ground) water;

- Integrative studies on the occurrences and pathways of persistent organic pollutants (POPs) in water-soil-air-food chain;
- Fundamental know-how and technologies to safeguard drinking water including risk assessment using chemical and biological monitoring tools (in-situ and off-site);

- Controlling emissions of fine particle (PM 10) and sulfur dioxide. In the future, the control of nitrogen oxides and fine particles will be emphasized. For basic research, pollution prevention for atmospheric oxidative species and secondary air pollutants are focused;

- Fundamental investigation on contaminant accumulation in key-food crops and the development of grass-root approach (from land to plates) to safeguard food safety.

We believe that most of the pressing environmental problems in China are most probably shared by many other countries, particularly by those with similar economic growth patterns, and thus it is important that research experience in environmental science and technology gained in China be disseminated to a wider community. On the other hand, a developing China also needs appreciation and recognition of its environmental problems and solutions, thus to facilitate the adoption of knowledge and novel technologies developed from outside. In this regard, we feel inspired to develop a special section on the State-of-Art in China hoping that it will serve as a platform for the communication between China and the outside world in respect to the developments of environmental science and technology.

Prof. Yong-Guan Zhu (Section editor 'State-of-Art in China')

- Head, Department of Soil Environmental Sciences

- Research Centre for Eco-environmental Sciences, Chinese Academy of Sciences

- Visiting Research Fellow, The University of Adelaide, Australia

Major research interests:

Plant ecology and nutrition; mycorrhizas; environmental contamination and remediation; restoration ecology

Education and qualification:

- July 1989: BSc in soil science and plant nutrition from Zhejiang University, Hangzhou, PR China

- July 1992: MSc in soils and environmental chemistry, the Institute of Soil Science, Chinese Academy of Sciences, PR China. Project on chemistry of potassium in tropical and subtropical areas of China

- June 1998: PhD in radioecology (environmental plant physiology) from the University of London (Imperial College). UK Project on potassium-radiocaesium interactions in soil-plant systems and remediation of radiocaesium-contaminated soils

- June 1998: Diploma of Imperial College (DIC), UK

Special functions:

- Member, Standing Advisory Group of Nuclear Applications, International Atomic Energy Agency (IAEA)

- Vice President, International Union of Radioecology

- Section editor, Plant and Soil

- Editorial board, Journal of Plant Nutrition

Editorial board, Environment international

- Secretary: COMMISSION 3.5 Soil degradation control, remediation and reclamation, International Union of Soil Science 